\title{
Determining the Magnitude of the Last Croatian Economic Recession
}

\author{
Djula Borozan \\ Faculty of Economics in Osijek, Josip Juraj Strossmayer University of Osijek
}

\begin{abstract}
An economic recession is commonly defined as a temporary contraction in aggregate economic activity in a country. It is observable in a decline of country's gross domestic product (GDP) for at least two consecutive quarters on a quarter-to-quarter basis. The decline in GDP is followed, among others, by declines in industrial production, retail sales, consumer spending and levels of employment. Each recession may be described by numerous features such as its length and depth or duration. In Croatia, the recession started in 2009 and lasted until 2015 on the yearly basis. Over that period, Croatia lost about 13 percent of its GDP. Due to its length and mean quarterly real GDP decline rate it was atypical compared to the recession recorded in most other countries.

This paper first aims at providing a theoretical background of economic recession. Then, after introducing Croatia's last recession as a case study, it aims at determining its magnitude. To that end, it employs a relatively simple calculation expression which takes into account the data on the quarterly real GDP growth rates and duration of the recession. The result shows that the recession in Croatia can be classified as a severe recession. Determining the magnitude of the recession in Croatia provides new insight into its structural economic features which may be of help for economic policy authorities. It also improves one's understanding of this big business, social, economic and policy challenge.
\end{abstract}

Keywords: Recession, Depresssion, Crisis, Croatia, Magnitude Evaluation 